Portland State University

PDXScholar

\title{
A Change in Pass/Fail Criterion on the Mini- Screening Language Test for Adolescents
}

Denice Lynn Palmer Milholland

Portland State University

Follow this and additional works at: https://pdxscholar.library.pdx.edu/open_access_etds

Part of the Educational Assessment, Evaluation, and Research Commons, and the Speech Pathology and Audiology Commons

Let us know how access to this document benefits you.

\section{Recommended Citation}

Milholland, Denice Lynn Palmer, "A Change in Pass/Fail Criterion on the Mini-Screening Language Test for Adolescents" (1982). Dissertations and Theses. Paper 3174.

https://doi.org/10.15760/etd.3165

This Thesis is brought to you for free and open access. It has been accepted for inclusion in Dissertations and Theses by an authorized administrator of PDXScholar. Please contact us if we can make this document more accessible: pdxscholar@pdx.edu. 
AN ABSTRACT OF THE THESIS OF Denice Lynn Palmer Milholland for the Master of Science in Speech Communication, with an emphasis in Speech Pathology/Audiology, presented May 19, 1982.

Title: A Change in Pass/Fail Criterion on the Mini-Screening Language Test for Adolescents.

APPROVED BY MEMBERS OF THE THESIS COMMITTEE:

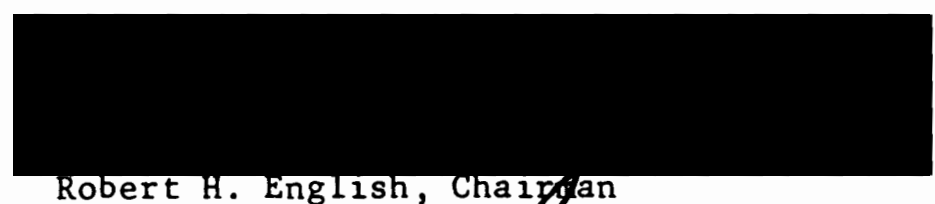

Robert H. English, Chalgyan

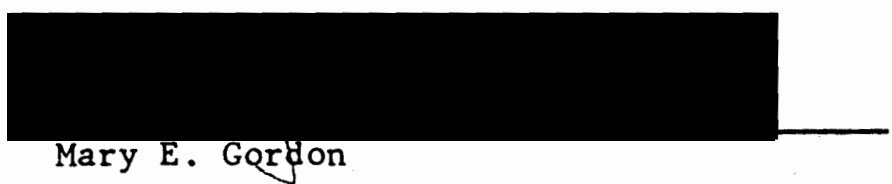

This study was designed to determine whether varying criterion for pass/fail on the Mini-Screening Language Test for Adolescents (Mini-STAL) would increase accuracy of predicting outcome of the Screening Test of Adolescent Language (STAL). The Mini-STAL was developed by Prather et al. (1981) to identify rapidly those students between grades six through twelve who are in need of language intervention. Using Prather's established criterion (one or more errors equal failure), the Phoenix school district (Prather, 1981) found too many of their school population (20 percent) were failing the MiniSTAL. Thus, they established an experimental criterion (two or more errors equal failure) to identify those students with language prob- 
lems. The present study sought to determine what proportion of students with language disorders was not detected by the Mini-STAL and what proportion of students without language disorders failed the Mini-STAL using the two criteria.

Subjects for this investigation were 287 students attending the seventh, eighth, and ninth grades at Raymond Brown Junior High School, Hillsboro School District, Hillsboro, Oregon, in the fall of 1981. Nineteen of these students were eliminated from the study due to the ambiguous nature of the manual in determining their pass/fail scores for Subtest IV (Proverb Explanation) on both tests, leaving a total of 268 subjects in the study.

The standardized instrument used to assess whether a student was in need of further diagnosis and/or intervention was the screening Test of Adolescent Language (STAL) by Prather et a1. (1980). Results of the STAL were compared with results of the Mini-STAL using the sets of criteria discussed above. Analysis of Prather's established criterion showed the Mini-STAL produced sixty-six false positives or 24.6 percent of those tested passed the Mini-STAL but failed the STAL. Four false negatives or 1.4 percent of the students failed the STAL and passed the Mini-STAL.

Analys is of the Phoenix experimental criterion revealed the Mini-STAL produced six false positives or 2.3 percent of those tested passed the Mini-STAL but failed the STAL. Eleven false negatives or 4.1 percent of those tested failed the STAL but passed the Mini-STAL. Prather's established criterion produced too large a proportion of false positives to be considered a valid screening test of language 
abilities, and the experimental Phoenix value produced too large $a$ proportion of false negatives to meet the standards for an ideal screening instrument. Thus, varying the criterion on the Mini-STAL does not increase the accuracy of predicting outcome of the STAL. Hence, this investigator would recommend utilizing the Prather criterion initially; then further screening of the false positives may be completed utilizing the STAL to reduce excessive false positives. This procedure would need to be tested empirically. 
A CHANGE IN PASS/FAIL CRITERION ON THE MINI-SCREENING LANGUAGE TEST

FOR ADOLESCENTS

by

DENICE LYNN PALMER MILHOLLAND

A thesis submitted in partial fulfillment of the requirements for the degree of

MASTER OF SCIENCE IN SPEECH COMMUNICATION:

with an emphasis in SPEECH PATHOLOGY/AUDIOLOGY

Portland State University

1982 
TO THE OFFICE OF GRADUATE STUDIES AND RESEARCH:

The members of the Committee approve the thesis of Denice Lynn Palmer Milholland presented May 19, 1982.
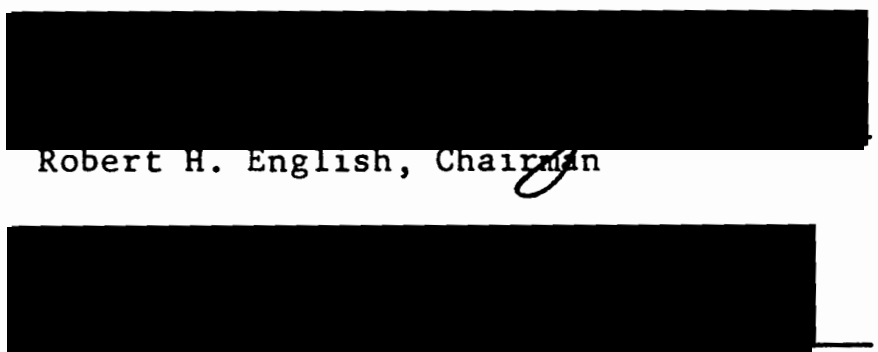

Mary E. Gordion

APPROVED :

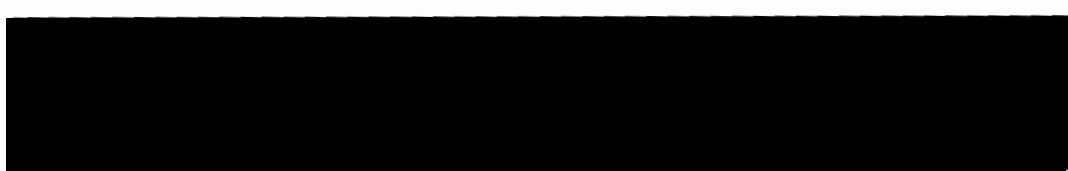

Theodore G. Grove, Head, Department of Speech Communication

Stanley E. Rauch, Dean, Graduate Studies and Research 


\section{ACKNOWLEDGEMENTS}

It is humbling to sit down and inventory my debts after writing a thesis. I suddenly realize how much I owe to others and how much more difficult the task would have been had I been forced to go it alone.

I owe, first of all, an enormous debt to my thesis comittee, Dr. Robert H. English, chairman, Mary E. Gordon, and Dr. Maron for their ideas, comments, and support.

of my colleagues, Janet Daucsavage, Laurel Hickman, and Molly Secrest have been particularly helpful in collecting my data. My appreciation is extended to Mary T. Withers for generously providing her time to supervise my data collection. To my support system, alter ego, and very best friend, Karen Kumpula-Lacey, thank you very much for always being there.

I was fortunate in being assisted by two wonderful families. Thank you not only for putting up with all the evenings and weekends I sat at home with pen in hand but also for your continuous encouragement and support.

Last, but not least, thanks to my love, my friend, my husband, Rand. This is, in a real sense, as much your thesis as mine, so strongly did you inspire me to stick it out. I love you. 
TABLE OF CONTENTS

Page

ACKNOWLEDGEMENTS ..................... . . . i i

LIST OF TABLES ...................... . . . vi

CHAPTER

I INTRODUCTION AND STATEMENT OF THE PROBLEM . . . . . . 1

Introduction . . . . . . . . . . . 1

Statement of the Problem .......... . 3

II REVIEW OF THE LITERATURE ... . . . . . . . . 4

Language and Language Disorders ........ . 4

Background to Identifying Language Problems .... 9

Language Screening Tests .......... 11

III METHODS AND PROCEDURES . . . . . . . . . . 16

Subjects ................ 16

Examiners .............. . 17

Testing Environment ........... 17

Procedures .............. . 17

Instruments . . . . . . . . . . . 19

Screening Test of Adolescent Language

Mini-Screening Language Test for Adolescents

Data Analysis . . . . . . . . . . 21

IV RESULTS AND DISCUSSION OF RESULTS . . . . . . . . 24

Results . . . . . . . . . . . 24 
Prather's Criterion

Phoenix School District Criterion

Discussion of Results... . . . . . . . . . 28

False Positives

False Negatives

Conclusion

V SUMMARY AND IMPLICATIONS . . . . . . . . . . . . 36

Summary . . . . . . . . . . . . . . 36

Implications . . . . . . . . . . . . 38

BIBL IOGRAPHY . . . . . . . . . . . . . . . . . . . 4 40

APPENDICES . . . . . . . . . . . . . . . . . . . . . 45 45

A PERMISSION REQUEST LETTER . . . . . . . . . . . 46

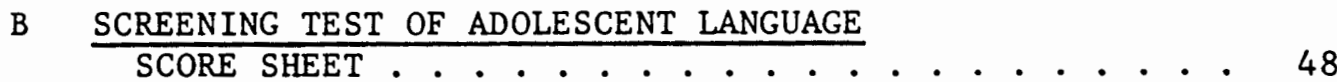

C MINI-SCREENING LANGUAGE TEST FOR ADOLESCENTS SCORE SHEET . . . . . . . . . . . . . . . . . 50 


\section{LIST OF TABLES}

TABLE

Page

I Test Score Results of the Selected Five Items from the STAL for Normal Achieving Sixth and Ninth Grade Students (Prather et al., 1981)......... 14

II Cut-off Scores for the STAL (Prather et al., 1980)..................... 22

II Mini-STAL Criteria for Pass/Fail . . . . . . . . . 23

IV Overall Test Score Results of the STAL and the Mini-STAL Using Prather's Criterion . . . . . . . . 25

V Overall Test Score Results of the STAL and the Mini-STAL Using the Phoenix Criterion . . . . . . . 27

VI Analysis of Items Missed on the Mini-STAL by 66 Subjects Using Prather's Criterion . . . . . . . . 30 


\section{CHAPTER I}

\section{INTRODUCTION AND STATEMENT OF THE PROBLEM}

\section{INTRODUCTION}

The identification of language disorders in the adolescent population has long been neglected (Byers Brown, 1976; Brenner, 1979; Prather, Breecher, Stafford, and Wallace, 1980; and Wiig and Semel, 1980). Until recently, there has been no standardized screening device to identify adolescents who require language intervention. Thus, many Speech-Language Pathologists have been forced to assess language skills of adolescents using informal measures. The student has been asked to describe an event, make up a story, or explain a concept, and then language ability is subjectively judged from the responses (Prather, Brenner, and Hughes, 1981).

A standardized language screening test designed to assess the expressive-receptive language abilities of adolescents is necessary to identify objectively those students with language problems. In addition to the obvious reason that it should be done, it would help meet requirements established by U.S. Congressional Public Law 94-142, The Education for All Handicapped Children Act of 1976. This law mandates that handicapped students be identified, assessed, and subsequently provided services; hence, the Speech-Language Pathologist is required to identify specifically those students with speech/language disorders. 
The importance of identifying adolescents with speech and language disorders generally has been overlooked by professionals. Notable exceptions are professionals such as Thorum (1979), Prather et a1. (1980, 1981), and Wiig and Semel (1976, 1980), all of whom have developed language tests specifically available for the adolescent population. Other tests (Dunn, 1965; Baker and Leland, 1967; and Mecham, Jex, and Jones, 1967) have been commonly used to assess language disordered adolescents; however, they were not designed for this population. Prather et al. (1981) note that one or more shortcomings associated with these latter tests are the following: 1) 1imited number of test items and/or normative subjects; 2) unrealistic length of administration; and 3 ) restriction to receptive language performance or 1 imited verbal response from students.

In 1980, Prather, Breecher, Stafford, and Wallace devised and standardized a Screening Test of Adolescent Language (STAL). The major disadvantage of the twenty-three item test is that it requires approximately seven minutes for administration, thus making it inappropriate for large scale screening. This time span allows the screening of only about forty-five students per day.

More recently, Prather, Brenner, and Hughes (1981) derived a mini-screening test from the STAL, the Mini-Screening Language Test for Adolescents (Mini-STAL). This test requires approximately one minute for administration, allowing identification of adolescents in need of language intervention through large scale screening. Using this screening test, it is estimated that three hundred students per day can be screened. 
In utilizing the Mini-STAL, a Phoenix, Arizona, school district found that too many students (approximately 20 percent of the junior high school population) failed the test (Prather, 1981). Typically, these students would then be referred for further diagnostic testing for possible language intervention. An examination of criteria for failure on the Mini-STAL reveals that missing one of the five items of the test results in failure. Since too many students failed the MiniSTAL for efficient use of clinical time, the Phoenix school district retested only those students who failed at least two of the five items. If criterion was set at missing two of the five items, instead of one (as established by the Phoenix, Arizona, school district), then perhaps the Mini-STAL might be a more accurate predictor of STAL performance .

\section{STATEMENT OF THE PROBLEM}

The purpose of this investigation was to determine the accuracy of predicting outcome of the Screening Test of Adolescent Language when varying the criterion for passing the Mini-Screening Language Test for Adolescents in screening seventh, eighth, and ninth grade students.

The two questions this investigation sought to answer were:

1. What are the estimated false positives; i.e., what proportion of students without language problems according to the STAL, will fail the Mini-STAL when the criterion is one error versus two errors?

2. What are the estimated false negatives; i.e., what proportion of students with language problems according to the STAL will not be detected by the Mini-STAL when the criterion is one error versus two errors? 
REVIEW OF THE LITERATURE

Conceptions of language and language disorders have changed tremendously over the last two decades. Thus, the need for new methods of language assessment is becoming crucial. Specifically, the study of language disorder has recently entered a population that has been very much neglected in this country, the adolescent population. There now exists the need for language screening instruments to serve this population. Language screening refers to a process of rapid assessment of a population in order to identify potential language disordered adolescent students. These students would then be referred for further diagnostic testing in order to identify those in need of language intervention.

The purpose of this review is threefold: 1) to discuss language and language disorders of the adolescent population; 2) to discuss the history of identifying language disorders; and 3) to discuss current language screening techniques.

\section{LANGUAGE AND LANGUAGE DISORDERS}

Research reveals a variety of ways to define language and language disorders, as well as the causes of these disorders (Carroll, 1953; Chomsky, 1965; Marge, 1972; Sitko and Gillespie, 1975; Baren, Lieb1, and Smith, 1978; Kleffner, 1978; Wiig and Seme1, 1980; and 
Gerber and Bryen, 1981). This disparity of opinion is often a result of the various disciplines such as audiology, speech-language pathology, special education, medicine, and optometry, which have contributed their specific viewpoints, insights, and vocabulary (Sitko and Gillespie, 1975). With such a variety of backgrounds, communication among disciplines tends to be confusing and complicated. This can be seen in the numerous labels that are used regarding language deficiency, such as: aphasia, language disorder, language delay, learning disability, psychoneurological learning disorder, autism, psychosis, and mental retardation. These words have lacked consistent and firm usage, thus becoming redundant, ambiguous, and contradictory. Within these same boundaries, Kleffner (1978) reports the existence of further dichotomies between diagnosis and treatment. These contradictions restrict the development of a consolidated approach to assessment. Knowledge about current conceptions of language and language disorders provides a basic foundation necessary to identify adolescents with language disorders. Language has been defined in numerous ways by numerous examiners, depending on their particular discipline. For example, Gerber and Bryen (1981) view language as a social code possessing a finite set of linguistic rules, having the potential for generating an infinite number of sentences. They write: ". . language is a rule-governed symbol system that is capable of representing or coding one's understanding of the world." This emphasis on coding is operative in other linguistic definitions of language, e.g., Carroll (1953), who defines language as:

A structured system of arbitrary vocal sounds which is used, or can be used, in interpersonal communication 
by an aggregation of human beings, and which rather exhaustively catalogs the things, events, and processes in the human environment.

Chomsky (1965), on the other hand, defines language from a psycholinguistic, transformational-generative point of view. Language, according to Chomsky, is an abstract system of knowledge in which a gramatical association exists between sound and meaning in a specific and complex manner. He divides this elaborate language system into syntactic, semantic, and phonological rules.

Similar to Chomsky (1965), several researchers divide language into components. Commonly, they are referred to as phonological, morphological, syntactical, and semantic components. These components must be acquired in order to understand and speak a language, and are observed indirectly through their effects on listening, speaking, reading, and writing. Various approaches reflecting each of these components of language and language behaviors are found in studies assessing language difficulties of adolescents (Gerber and Bryen, 1981).

Just as language has been defined in many ways, so it is with language disorder. Baren, Liebl, and Smith (1978) view students with language disorders as having ". . some type of dysfunction in the various mechanisms necessary for the understanding, processing or expression of language." Heward and Or lansky (1980) divide language disorders into three categories: 1) receptive; 2) expressive; and 3) delay. The 1977 Federal Register specifies that language problems include deficient skills in oral expression, listening comprehension, and written expression. Neidecker (1980) defines language disorder as 
abnormal acquisition, comprehension, or use (including all receptive and expressive language ski11s) of spoken or written language.

According to Myklebust (1964) and Wood (1969), approximately 5 percent of school-age children have language problems severe enough to interfere with education. This estimate involves approximately ten million students in the United States (Perkins, 1977). The National Advisory Neurological Diseases and Stroke Council (1969), however, estimated prevalence of language disorders to be only two million children or approximately 1 percent of school-age children in the United States. These varying results may be related to the numerous definitions of language disorder in the literature. No published prevalence estimates of language disorder, specifically in the adolescent population, are available.

Baren et al. (1978) list the following causes which have been attributed to language disorders: genetic; hereditary; infectious; traumatic; nutritional; and emotional. Researchers have become more concerned, however, with the processes that may be disturbed in language disordered adolescents (Wiig and Semel, 1976, 1980) rather than with describing each group.

Language disorders are characterized by many different signs and symptoms. It is extremely important to consider the category of language disorder when evaluating a student who shows such behaviors as: inattention; excessive activity; poor reading; general learning difficulty; problems following directions; noise making; shyness; disruptiveness; and other behavioral problems. According to Baren et al. (1978), language disability can be a "great masquerader" and is often 
categorized in the learning disability realm.

Historically, researchers in the field of learning disabilities have concentrated their interest on visuo-perceptual problems; however, a concern for language problems also is evident. Language disorders associated with learning disabilities have been reported in the literature by Orton (1937); Myklebust (1954); Strauss and Kephart (1955); Cruickshank, Bentzen, Ratzeburg, and Tannhauser (1962); Bannatyne (1971); Wiig and Harris (1974); and Wiig and Semel (1974, 1976). According to Sitko and Gillespie (1975), language disorders have been considered as symptoms of a learning disability, as well as the cause. Not only do authors feel language problems are disproportionately present in the learning disabled population (Gerber and Bryen, 1981), but also the definition of learning disabilities presented in U.S. Congressional Public Law 91-230, The Children with Specific Learning Disabilities Act of 1969, implies that language is paramount to the problems of this population:

- . disorder in one or more of the basic psychological processes involved in understanding and/or in using spoken or written language.

McGrady (1968) and Marge (1972) estimate 50 percent of such learning disabled individuals have language deficits.

Language problems become most evident during the preschool and elementary years; thus, the study of language disorders tends to center around this population of students. What happens to these students as they approach junior and senior high schools? A review of the literature reveals a paucity of published data on the later fate of these students. Jones and Healey (1974) report meager information 
exists on actual prevalence or incidence of adolescents with depressed or disordered language skills. The growing awareness of language disorders in the adolescent population has resulted in: 1) a realization that most Speech-Language Pathologists have no frame of reference with which to carry out assessment; 2) there are few, if any, adequate instruments for carrying out diagnosis; and 3 ) there is no logical basis for translating assessment results into effective teaching programs.

\section{BACKGROUND TO IDENTIFYING LANGUAGE PROBLEMS}

Neidecker (1980) discusses two processes utilized for identification of language problems: these are referral and screening. These processes may be implemented either singly or in combination. Referrals consist of alerting the school clinician that a particular student might have a language problem. On the junior and senior high school levels, self-referrals are more evident (Gordon, 1981). Public Law 94-142 requires that all students needing diagnostic assessment be identified. Screening is the most widely used method in this identification process (Mercer, 1979). Packouz (1975) defines screening as a procedure used to evaluate a large population of students to identify those who potentially have language problems. The purpose of screening, according to Neidecker (1980), is threefold: 1) to determine whether a problem exists; 2) to determine whether further evaluation is required; and 3 ) to determine if referral to other professions is required.

Neal (1976) conducted a study of speech pathology services in 
the secondary schools. His results indicate that screening was the most prevalent case-finding procedure in elementary schools, whereas, referrals by teachers were most frequently used in the secondary grades. Difficulties in implementing a screening program, resulting from inflexible junior and senior high school schedules, were thought to contribute to these results (Neidecker, 1980).

According to Gerber and Bryen (1981), assessment for screening purposes should provide information demonstrating how a student's performance in a given area of language conforms to normative data for that given age group. Typically, this information is presented in forms such as percentiles and/or language ages.

Important considerations necessary for screening emphasized by Task Force Report (1973) include: quickness; pass/fail accuracy; and an accurate statement of the goal accomplished by the screening. Rosenburg (1970) emphasizes the need for language assessment devices based on recent, valid, theoretical, methodological, and research developments in the language sciences. Hamilton (1974) comments that both reliability and validity of rapid screening procedures should be tested frequently, illustrating false positive and false negative rates of less than 1 percent.

The best methodology to use for screening is still under scrutiny. Should one use spontaneous language samples or elicit repetitions of language forms for analysis? While no one has provided conclusive answers, Gerber and Bryen (1981) report the test format ideally should be as closely related as possible to the natural use of language, yet still provide valuable information. Thus, a distinction 
must be made between screening techniques that are structured and those based on the analysis of the spontaneous use of language. Gerber and Bryen (1981) believe a structural technique may sacrifice information concerning how a child uses language naturally, and a spontaneous language sample may not be valid because the linguistic structure in question may not occur.

While the search continues for determining language comprehension and expression in the clinic, school, hospital, etc., Speech-Language Pathologists must utilize what is currently available.

\section{LANGUAGE SCREENING TESTS}

With the increasing interest in the area of language assessment during the past two decades, many language assessment instruments have been developed. Most of these instruments were designed to serve the age range between four and twelve (Thorum, 1981); however, recently several tests have appeared which may be considered as possible screening tests for adolescent language. To gain further insight into the current state of the art of adolescent language screening, an overview of these tests will be presented below.

Three tests currently available specifically to screen the adolescent population for language disorders are: Clinical Evaluation of Language Functions (CELF); Screening Test of Adolescent Language (STAL); and Mini-Screening Language Test for Adolescents (Mini-STAL).

The CELF has been adapted by its authors, Wiig and Semel (1980), for use as a screening device, as well as a diagnostic instrument. The advanced level screening test is used to assess fifth through 
twelfth grade students. It looks at both receptive and expressive skills for language processing and language production. Normative data were collected on one hundred students per grade level for a total of 1,405 students representative of the 1970 United States Census data. Reliability and validity studies were conducted. The disadvantage of this screening instrument is the administration time of twenty minutes. This time span would allow only two students per class period or approximately fifteen students per day to be screened, thus failing to meet the consideration of time efficiency necessary in selecting a screening instrument, as recomended in the Task Force Report (1973).

The STAL, developed by Prather, Breecher, Stafford, and Wallace (1980) to identify students needing further diagnostic evaluation, taps several language skills determined by Wiig and Semel (1976) to be associated with learning/language disabilities. These skills are: word finding and retrieval abilities; memory span (associated with related semantic and syntactic stimuli); decoding messages; language reasoning; problem solving; paraphrasing ability; and cognitive skills needed for verbal clarity. The STAL is designed for use with sixth through twelfth grade students. It was standardized on $206 \mathrm{sixth}$ grade students and 219 ninth grade students from the Phoenix, Arizona, area. Prather et al. (1980) also utilized a learning disability population for standardization. Reliability and validity studies were conducted. The validity of the STAL was established utilizing thirtyeight ninth grade students who scored across the range from low to high on the STAL. Four subtests of the Detroit Tests of Learning 
Aptitude (DTLA) by Baker and Leland (1967) were administered as the instrument for validity correlation. These subtests include: Verbal Opposites; Auditory Attention Span for Related Syllables; Verbal Absurdities; and Likenesses and Differences. The Pearson productmoment correlation between the total STAL score and the total raw score across the four DTLA subtests was +.86 .

To determine reliability of the STAL, the authors (Prather et a1., 1980) readministered the test to thirty students one month later. The Pearson product-moment correlation coefficient between the two sets of scores was determined to be +.98 .

Disadvantages to this screening instrument include: a limited age range utilized in the standardization and validation studies, and conduction of the standardization and validation studies within a limited geographical area (Phoenix, Arizona). Another disadvantage to this screening instrument is the administration time. The STAL requires seven minutes to administer. This time span allows the screening of only about forty-five students per day, thus making it inappropriate for large scale screening.

More recently, Prather, Brenner, and Hughes (1981) derived a mini-screening test from the STAL, the Mini-Screening Language Test for Adolescents (Mini-STAL). It is composed of five items extracted from the STAL via an item analysis. To determine whether the selected five items accurately predicted pass/fail of the total STAL, Prather et al. (1981) rescored previously administered STAL tests. They looked only at the five items selected for the Mini-STAL. The test score results of the selected five items from the STAL for normal 
achieving sixth and ninth grade students can be seen in Table I.

The disadvantage to this mini-screening test is the exceedingly large number of false positives (13 percent) or those students who failed the mini-screening test but passed the STAL. According to Hamilton (1974), the ideal screening test should not exceed 1 percent false positive and false negative rates. The advantage of the MiniSTAL is that it requires approximately one minute for administration. This time span would allow a Speech-Language Pathologist to screen approximately three hundred students per day.

\section{TABLE I}

TEST SCORE RESULTS OF THE SELECTED FIVE ITEMS FROM THE STAL FOR NORMAL ACHIEVING

SIXTH AND NINTH GRADE STUDENTS

(PRATHER ET AL., 1981)

\begin{tabular}{|c|c|c|c|}
\hline & \multicolumn{2}{|c|}{ STAL } & \multirow[b]{2}{*}{ Subtota 1} \\
\hline & Fail & Pass & \\
\hline $\begin{array}{ll}\text { M } & \\
\mathrm{I} & \text { Fail } \\
\mathrm{N} & \\
\mathrm{I} & \end{array}$ & $\begin{array}{l}\text { Agreed } \\
9-10 \%\end{array}$ & $\begin{array}{c}\text { False + } \\
13 \%\end{array}$ & $22-23 \%$ \\
\hline $\begin{array}{l}\mathrm{S} \\
\mathrm{T} \\
\mathrm{A} \\
\mathrm{L}\end{array}$ & $\begin{array}{c}\text { False - } \\
2-3 \%\end{array}$ & $\begin{array}{l}\text { Agreed } \\
74-75 \%\end{array}$ & $76-78 \%$ \\
\hline Subtotal & $11-13 \%$ & $87-88 \%$ & $\begin{array}{r}\text { Total } \\
100 \%\end{array}$ \\
\hline
\end{tabular}

Additional tests often are utilized in screening adolescent language, but they were not designed specifically for this population. These tests consist of the Peabody Picture Vocabulary Test (PPVT), 
Detroit Tests of Learning Aptitude (DTLA), Illinois Test of PsychoIinguistic Ability (ITPA), and the Utah Test of Language Development (UTLD). Many criticisms have been leveled at these tests. Sitko and Gillespie (1975) question the ITPA's (Kirk, McCarthy, and Kirk, 1969) rationale, validity, and reliability. Irwin, Moore, and Ramps (1972) criticize the PPVT (Dunn, 1965) for its assessment of students' receptive language skills only. The UTLD (Mecham, Jex, and Jones, 1967) directs most of its items to the preschool level, thus inadequately representing the adolescent population. Finally, the DTLA (Baker and Leland, 1967) requires lengthy administration time.

It has been noted in the foregoing review of the literature that there now exists the need for additional screening instruments to serve the adolescent population. More specifically, screening tests are needed that are not only fast but also reliable, valid, and standardized with efficient cut-off scores. The Mini-STAL is able to be utilized in large scale screening; however, it does not provide accurate pass/fail information. The present study was designed, in effect, to help determine the efficiency of the cut-off scores on the Mini-STAL. Specifically, what is the comparative, overall accuracy of prediction when varying the criterion for pass/fail? 


\section{METHODS AND PROCEDURES}

The following is a discussion of the methods and procedures that were utilized in the present study. More specifically, the ensuing discussion is organized under the following subtopical headings:

Subjects; Examiners; Testing Environment; Procedures; Instruments; and Data Analysis.

\section{SUBJECTS}

The subjects of this study were selected from students who were currently attending seventh, eighth, and ninth gradesat Raymond Brown Junior High School, Hillsboro School District, Hillsboro, Oregon, in the Fall of 1981. Permission was obtained from the parent or guardian of each subject prior to participation in the study (see Appendix A for Permission Request Letter). All students were tested upon return of their parent permission slips. The students were selected by the random order in which the permission slips were returned.

For the purpose of the present investigation, an adolescent population was defined as those students enrolled in seventh, eighth, and ninth grades. No attempts were made to control for intelligence, socioeconomic level, or sex. 
EXAMINERS

In addition to the writer, three individuals served as examiners. These examiners were graduate students currently completing requirements within the Speech and Hearing Sciences Program, Department of Speech Communication, Portland State University.

In order to calibrate administration techniques, the investigator trained the additional examiners in standard administration procedures. The examiners recorded student responses verbatim. Test administration was under the supervision of a Speech-Language Pathologist with the Certificate of Clinical Competence (CCC) in SpeechLanguage Pathology.

\section{TESTING ENVIRONMENT}

Screening took place within three consecutive school days during September 1981. Each student was seen individually for approximately eight minutes. Testing took place from two chairs set-up in the hall outside the classrooms. Each student, in turn, was seated directly across from the examiner.

\section{PROCEDURES}

Parental permission slips were collected and subjects selected. Two tests were administered to each student, the Screening Test of Adolescent Language (STAL) and the Mini-Screening Language Test for Adolescents (Mini-STAL) by Prather et al. (1980, 1981). Scoring was done by the investigator at the conclusion of all testing. The order of presentation for the two tests was assigned on a random basis by 
systematically alternating the presentation so that half of the subjects received the Mini-STAL first. Prior to testing, each student was assured by the examiner that: 1) the screening tests were not graded school tests and the examiner was not a school employee; and 2) that some questions might be repeated, and this would not imply failure.

At the time of testing each student was asked to give his/her name, birthdate, and race. Sex was recorded by the examiner. The examiners were not acquainted with any of the subjects, and had no information about their previous language or academic performance.

Instructions from the test manual were given verbally to each student at the beginning of each subtest. One variation was made in giving verbal instructions from the manual on Subtest III (Language Processing). The manual instructs the examiner to say: "I will read a sentence and I want you to tell me two things: What does not make sense and why it does not make sense. Listen carefully; I can only read this once." According to the manual, if a partial response is given, the examiner may prompt with "Why doesn't that make sense?" To reduce inconsistent administration this examiner elected to routinely include the prompt after the stimulus sentence was read, for example:

- . THE SUN WAS SHINING So BRIGHTLY LAST WEEK ON TUESDAY THAT I HAD TO WEAR MY SUNGLASSES IN THE MOVIE THEATER.

EXAMINER WOULD THEN PROMPT: WHAT DOES NOT MAKE SENSE? Ipause 7 WHY DOESN'T THAT MAKE SENSE? Ipause-T

All examiners were instructed to include the prompt. Subject responses were recorded verbatim on the score sheets by the examiner. 


\section{INSTRUMENTS}

The instruments utilized in the present investigation were the STAL and the Mini-STAL. Each test is described in detail below.

\section{Screening Test of Adolescent Language}

The STAL was designed for use with upper elementary through high school students. It includes twenty-three items which test both expressive and receptive language abilities (see Appendix B for a copy of the Score Sheet). Time required for administration is approximately seven minutes. No pictures or objects are required for administration. Scoring time requires approximately one minute.

The STAL is divided among four subtests as follows: Vocabulary; Auditory Memory Span; Language Processing; and Proverb Explanation. Prather et a1. (1980) selected these particular subtests to assess several language skills that Wiig and Semel (1976) associate with learning/language disabilities. The Vocabulary Subtest assesses word finding and retrieval abilities of the student. Each word is read to the subject and then immediately followed by a three to eight word sentence containing the stimulus word. The subject is then asked to give another word for the stimulus word which means the same thing and fits appropriately in the sentence. A guide to correct responses is provided in the manual; however, regional colloquialisms and synonyms may be judged correctly as deemed by the examiner. The items are scored correct or incorrect.

Aspects of the student's memory span are assessed with the Auditory Memory Span Subtest. It is comprised of three sentences, each 
containing fifteen to sixteen words. After a sentence is read to the subject, he is asked to repeat it verbatim to the examiner. A sentence containing three or more errors (substitutions, additions, or omissions) is scored incorrect.

The student's ability to decode a message and to use language for problem solving is examined in the Language Processing Subtest. This subtest consists of five sentences that consist of either an absurd or incorrect idea. The subject is required to respond to each orally read sentence by answering the following two part task:

1) What does not make sense? and 2) Why does it not make sense?

Guidelines for correct responses are in the manual; however, subjective judgment on the part of the examiner is relied upon. Both concepts must be answered correctly to be scored correct.

The Proverb Explanation Subtest requires the student to paraphrase. This, in turn, examines the student's cognitive skills necessary for verbal clarity. Three proverbs are given, ranging in length from three to five words. The subject is asked to tell what each proverb means. An item is scored correct if the subject verbally demonstrates comprehension of the meaning of the proverb. Again, guidelines are provided in the manual, but subjective judgment by the examiner is relied upon heavily.

Failure of an individual on the STAL is determined by one or both of the following: 1) total test score; and 2) individual subtest scores. Thus, when computing pass/fail results, the examiner must compare two types of scores, the total test score and the individual subtest scores with the cut-off scores provided. 
A score is computed for each subtest. These scores are then totaled to give the total test score. Both scores must be compared with the cut-off scores provided to determine whether the student has passed or failed each section or the total test (refer to Table II). The STAL was standardized on 206 sixth grade students and 219 ninth grade students from the Phoenix, Arizona, area, as we 11 as 32 junior high school students and 90 senior high school students in learning-disabled classrooms.

\section{Mini-Screening Language Test for Adolescents}

The Mini-STAL was derived from the larger STAL for use as a rapid screening device. It is composed of five items selected from the STAL: two vocabulary items; and one item from each of the remaining three subtests (see Appendix $C$ for a copy of the Score Sheet). For a discussion of what each subtest measures, refer to the STAL section above. Failure of one of the five items results in failure of the screening test.

The Mini-STAL was derived totally from an item analysis of data obtained in the standardization of the complete STAL. The five items selected were passed by the majority of students at each grade level. Prather et al. (1981) reasoned that failure of one of these items resembles failure of the corresponding subtest.

\section{DATA ANALYSIS}

In the present study, criteria for pass/fail on the Mini-STAL were compared using two cut-off scores: following the criterion established by Prather et al. (1981), failure on the Mini-STAL con- 


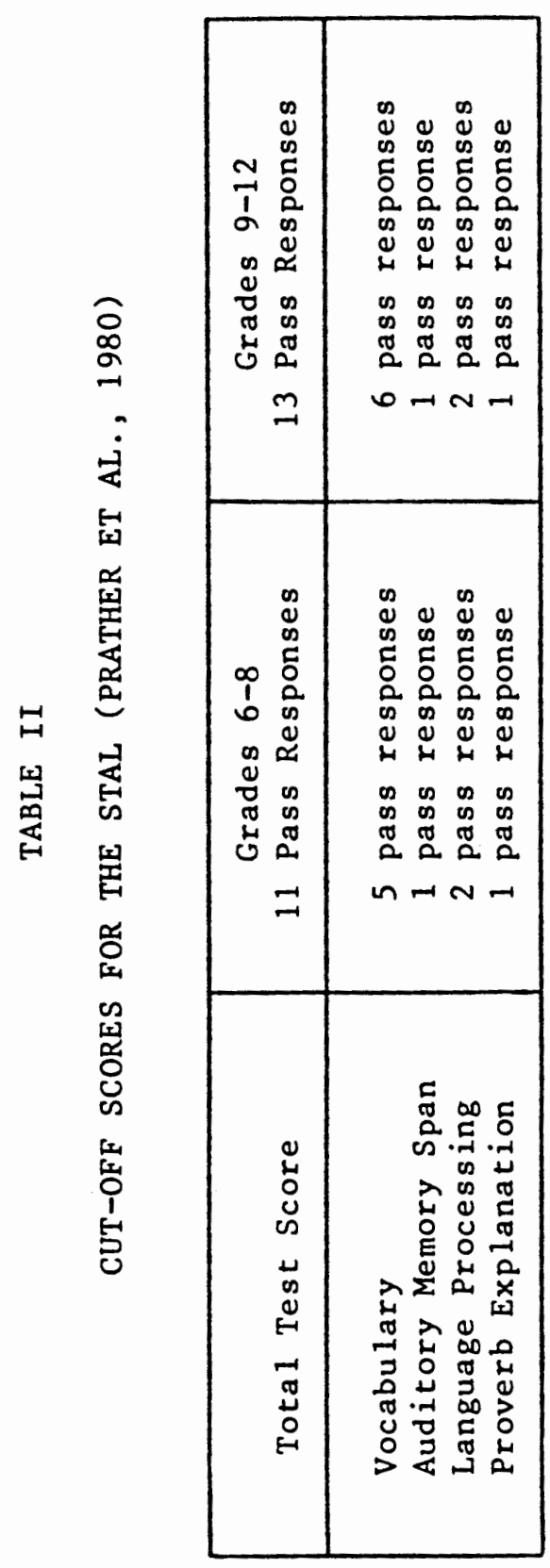


sisted of failure on one or more items; and following criterion estab1ished by the Phoenix, Arizona, school district (Prather, 1981), failure on the Mini-STAL consisted of failure on two or more items. Thus, each student was judged according to two pass/fail criteria on the Mini-STAL (see Table III).

TABLE III

MINI-STAL CRITERIA FOR PASS/FAIL

\begin{tabular}{|c|c|}
\hline $\begin{array}{c}\text { Prather's } \\
\text { Criterion for Pass/Fail }\end{array}$ & $\begin{array}{l}\text { Phoenix School District } \\
\text { Criterion for Pass/Fail }\end{array}$ \\
\hline Pass: 5 pass responses & Pass: 4 or more pass \\
responses \\
Fail: 1 or more errors & Fail: 2 or more errors \\
\hline
\end{tabular}

These results were then compared with the pass/fail results obtained from the STAL (total test score and subtest score) to determine: 1) the number of false positives, those students with no language problems according to the STAL, but failed the Mini-STAL; and 2) the number of false negatives, those students with language problems according to the STAL, but were undetected by the Mini-STAL. The results and conclusions from these tests are discussed in Chapter IV. 


\section{CHAPTER IV}

\section{RESULTS AND DISCUSSION OF RESULTS}

\section{RESULTS}

Results from the Mini-Screening Language Test for Adolescents (Mini-STAL) were compared using two sets of pass/fail criteria. Criterion consisting of Prather's established pass/fail values ( $5=$ pass; 4 or less=fail) will be referred to as "Prather's criterion." The comparison criterion consisted of the Phoenix public school district's experimental values $(4-5=$ pass; $0-3=$ fail) and will be referred to as the "Phoenix criterion." Concurrently administered with the Mini-STAL was the Screening Test of Adolescent Language (STAL) to serve as a standardized control instrument. Tables were generated to describe and compare the collective data from these instruments.

The results were compared according to: 1) the number of false positives, those students who passed the STAL but failed the screening test (Mini-STAL) using both Prather's criterion and the Phoenix criterion; and 2) the number of false negatives, those students who failed the STAL but passed the Mini-STAL using both the Prather and Phoenix criteria.

The cut-off scores for pass/fail on the STAL (control instrument) differed for two populations. Students in grades nine through twelve required at least thirteen pass responses, whereas those students in grades six through eight required only eleven pass responses 
(see Table II, Chapter III). Students in both populations were assessed in this study, i.e., 7 th- 8 th grade students and 9 th grade students; thus, data from these two samples were analyzed separately. The product of all subjects examined was then determined to provide the overall results displayed in Tables IV and $V$.

Prather's Criterion

The overall results displayed in Table IV are the product of all subjects examined using Prather's criterion.

TABLE IV

OVERALL TEST SCORE RESULTS OF THE STAL AND THE MINI-STAL USING PRATHER'S CRITERION

\begin{tabular}{|c|c|c|c|}
\hline & \multicolumn{2}{|c|}{ STAL } & \multirow[b]{2}{*}{ Subtota 1} \\
\hline & Fail & Pass & \\
\hline $\begin{array}{ll}M & \text { Fail } \\
\text { I } & \\
N & \\
\text { I } & \end{array}$ & $\begin{array}{c}\text { Agreed } \\
16 \\
(6.0 \%)\end{array}$ & $\begin{array}{c}\text { False + } \\
66 \\
(24.6 \%)\end{array}$ & $\begin{array}{c}82 \\
(30.6 \%)\end{array}$ \\
\hline $\begin{array}{ll}\text { S } & \\
\text { T } & \\
\text { A } & \text { Pass } \\
\text { L } & \end{array}$ & $\begin{array}{c}\text { Fa1se - } \\
4 \\
(1.4 \%)\end{array}$ & $\begin{array}{c}\text { Agreed } \\
182 \\
(68.0 \%)\end{array}$ & $\begin{array}{c}186 \\
(69.4 \%)\end{array}$ \\
\hline Subtotal & $\begin{array}{c}20 \\
(7.5 \%)\end{array}$ & $\begin{array}{l}248 \\
(92.5 \%)\end{array}$ & $\begin{array}{c}\text { Tota } 1 \\
268 \\
(100 \%)\end{array}$ \\
\hline
\end{tabular}


Results shown in Table IV assist in answering the specific questions posed in this study utilizing Prather's criterion:

1. What are the estimated false positives; i.e., what proportion of students without language problems according to the STAL, failed the Mini-STAL when the criterion consisted of one error?

Results: Prather's criterion produced 66 false positives or 24.6 percent of those tested. Thus, 24.6 percent of the sample tested who passed the STAL failed the Mini-STAL. This means that 66 out of 268 students would have to be tested with a diagnostic test needlessly.

2. What are the estimated false negatives; i.e., what proportion of students with language problems according to the STAL, were not detected by the Mini-STAL when the criterion was one error?

Results: Prather's criterion produced four false negatives or 1.4 percent of those tested. These results indicate that 1.4 percent of the sample tested who failed the STAL passed the Mini-STAL. Using the Mini-STAL alone 4 out of 268 students would pass unidentified through the screening.

Table IV also reveals the number and percentage of subjects who passed both tests or failed both tests, i.e., those tests which were in agreement. An ideal screening instrument would indicate 100 percent of the students in agreement with the control test. That is, either the students should fail both tests or pass both tests. The combined results, using Prather's criterion, show 198 or 74 percent of the subjects received similar scores on both tests.

\section{Phoenix School District Criterion}

Overall results displayed in Table $V$ are the product of all subjects examined using the Phoenix criterion.

Utilizing the Phoenix criterion, results shown in Table $\mathrm{V}$ assist in answering the specific questions posed by the present study: 
TABLE V

OVERALL TEST SCORE RESULTS OF THE STAL AND THE MINI-STAL USING THE PHOENIX CRITERION

\begin{tabular}{|c|c|c|c|}
\hline & \multicolumn{2}{|c|}{ STAL } & \\
\hline & Fail & Pass & Subtota 1 \\
\hline M Fail & Agreed & False & \\
I & 9 & 6 & 15 \\
N & $(3.3 \%)$ & $(2.3 \%)$ & $(5.6 \%)$ \\
I S & & & \\
T & False & Agreed & 253 \\
A & 11 & 242 & $(94.4 \%)$ \\
Pass & $(4.1 \%)$ & $(90.3 \%)$ & Total \\
& & 20 & $(100 \%)$ \\
\hline
\end{tabular}

1. What are the estimated false positives; i.e., what proportion of students without language problems according to the STAL, failed the Mini-STAL when the criterion was two errors?

Results: The Phoenix criterion produced 6 false positives or 2.3 percent of those tested. Thus, 2.3 percent of the sample tested who passed the STAI failed the Mini-STAL. This means that only 6 out of 268 students would have to be reexamined using a diagnostic test.

2. What are the estimated false negatives; i.e., what proportion of students with language problems according to the STAL, were not detected by the Mini-STAL when the criterion was two errors?

Results: The Phoenix criterion produced 11 false negatives or 4.1 percent of those tested. These results indicate that 4.1 percent of the sample tested who failed the STAL passed the Mini-STAI. This means that 11 out of every 268 students tested would go without needed services. 
Table $\mathrm{V}$ also reveals the number and percentage of subjects who passed both tests or failed both tests, i.e., those tests which are in agreement. The combined results, using the Phoenix criterion, show 251 or 93 percent of the subjects received similar scores on both tests.

\section{DISCUSSION OF RESULTS}

This study sought to determine the accuracy of predicting the outcome of the Screening Test of Adolescent Language (STAL) when varying the criterion for passing the Mini-Screening Language Test for Adolescents (Mini-STAL) in screening seventh, eighth, and ninth grade students. Overall results cited in the foregoing section indicate that the Phoenix criterion significantly reduced the number of false positives (2.3 percent) as compared to Prather's criterion ( 24.6 percent). With the reduction of false positives using the Phoenix criterion, however, an increase in false negatives resulted; i.e., those who passed the screening test (Mini-STAL) but failed the control test (STAL). The Phoenix criterion showed 4.1 percent of the students tested as false negatives or about 11 out of every 268 students. Prather's criterion in comparison reduced the number of false negatives to 1.4 percent or about 4 out of every 268 students.

\section{False Positives}

An ideal screening test is one which will identify all students in need of a thorough diagnostic evaluation and/or inclusion in an intervention program (Packouz, 1975). Such a test, however, should not identify an excessive number of students who are not in need of 
diagnosis and for intervention. Sixty-six students needed further testing according to the Mini-STAL using Prather's criterion, yet were considered normal when the STAL was administered. These results exceed those reported by Prather et al, in 1981 (see Table I, Chapter II). They acknowledge that the Mini-STAL is ". . more selective of failure than the total test..." and estimate 13 to 20 percent of the students who probably have normal language will need to be reexamined. This investigation produced 24.6 percent of the sample tested that would require needless reexamination by a diagnostic instrument. A simple numerical analysis was done for items missed on the Mini-STAL to determine possible contributing factors to the high level of false positives occurring when using Prather's criterion. Results of this analysis are presented in Table VI.

Looking at Table VI, the most errors (34) occurred on the second vocabulary item of Subtest I on the Mini-STAL. As mentioned earlier, this particular subtest taps word finding and retrieval competencies. The examiner read the stimulus word "plump" followed by a four word sentence containing the stimulus word, i.e., "The child is plump." The student was asked to give another word that means the same thing and fits into the sentence. Of the thirty-four students who missed this item, fifteen incorrectly replaced "plump" with the word "big." The next most common incorrect answer was "large" given by twelve students, followed by "round" given by four students. These errors do not constitute extremely serious deficiencies in word finding/retrieval competencies. The remaining three incorrect answers were "tender," "husky," and "hefty." 


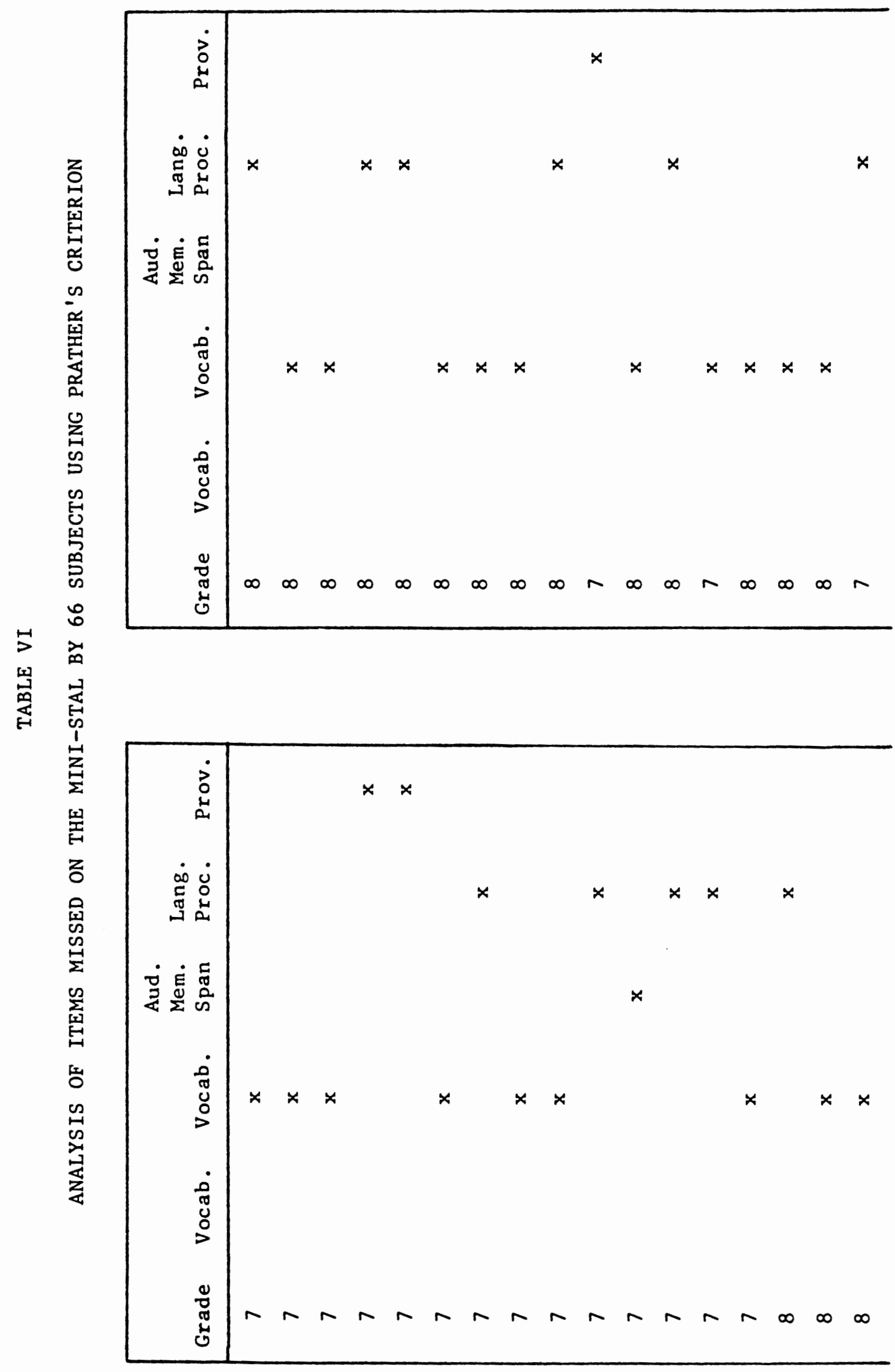




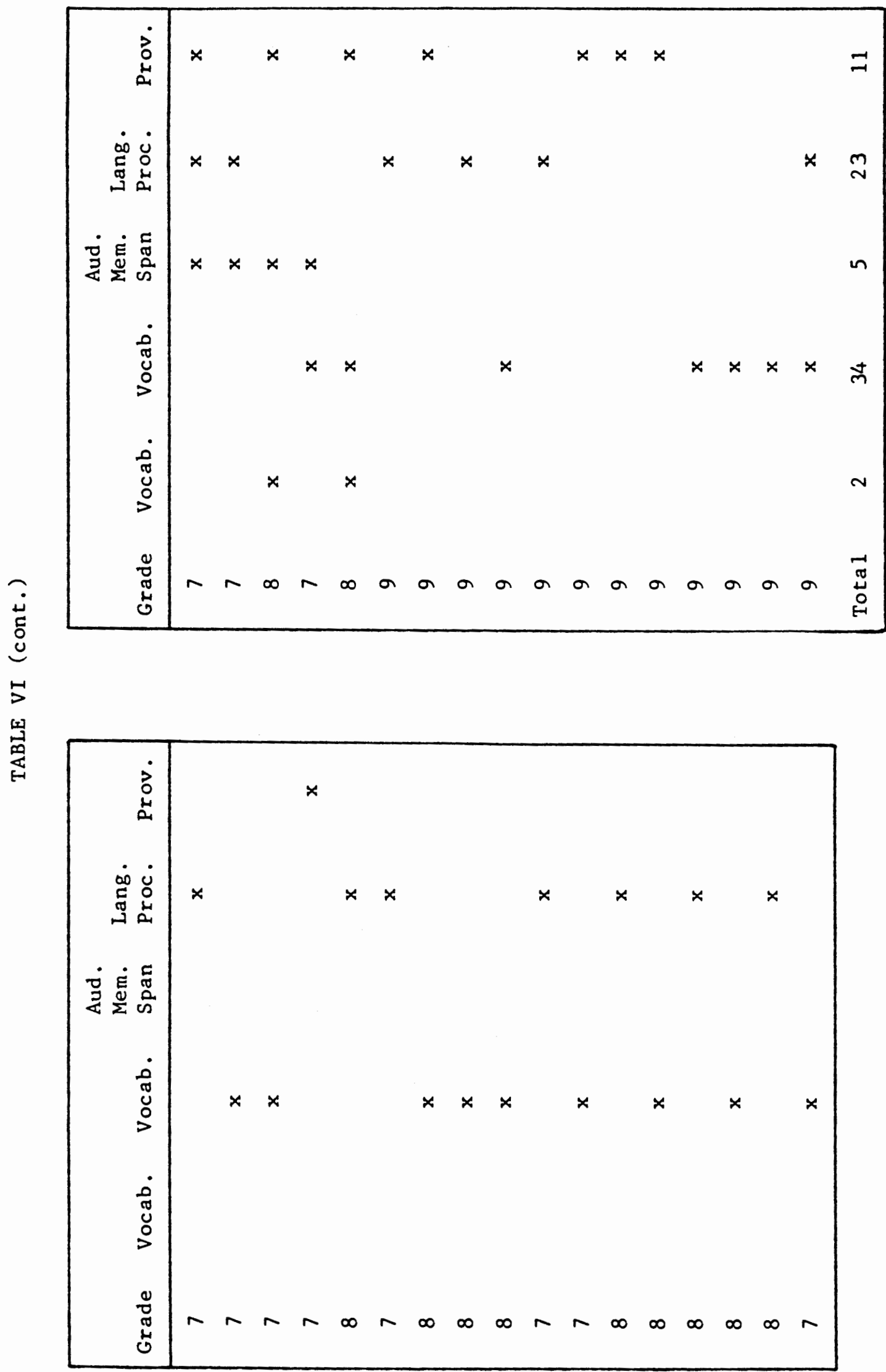


A large number of errors (23) also resulted from the language processing (Subtest III) task on the Mini-STAL. This task examines the student's ability to decode a message and then to use reasoning and problem solving abilities. The examiner instructs the student to respond to the orally read sentence ("The sun was shining so brightly last week on Tuesday that I had to wear sunglasses in the movie theater.") by following a two-part task: 1) What does not make sense? and 2) Why does it not make sense? Most students (17/23) failed to provide a sufficient reason as to why the sentence did not make sense. An example of an incomplete response is as follows:

EXAMINER: WHAT DOES NOT MAKE SENSE?

STUDENT: THAT THE SUN WAS SHINING IN THE THEATER. Lerrect $\bar{T}$

EXAMINER: WHY DOESN'T THAT MAKE SENSE?

STUDENT: BECAUSE YOU DON'T WEAR SUNGLASSES INTO A MOVIE THEATER. IincompleteT

Given this incomplete answer, the examiner would attempt to pursue further information; however, the student often replied with the same sentence, that he/she did not know, or with an equally incomplete, or irrelevant answer.

It is to be noted that errors were made on the remaining three items; however, they were relatively few in comparison with the previously discussed items.

The Phoenix criterion significantly reduced the number of false positives from 24.6 percent to 2.3 percent. Thus, reducing the difficulty for passing the Mini-STAL seems to result in a satisfactory reduction in number of false positives. 
False Negatives

The number of false negatives (those students who passed the Mini-STAL but failed the STAL) represents a most significant aspect in analyzing a screening device. According to Prather et al. (1981), these are the "real errors" and represent those students who would benefit from intervention but are slipping through the screening device. Using Prather's criterion, four students needed further diagnostic evaluation according to the STAL but were undetected by the Mini-STAL. As mentioned earlier, Hamilton (1974) indicated the ideal test would be one which had rates less than 1 percent for false positives and false negatives. Prather's criterion produced 1.4 percent false negatives, thereby exceeding the ideal rate of false negatives by only .4 percent.

In comparison, the Phoenix criterion failed to detect eleven students which, according to the STAL, were in need of further diagnostic evaluation. The Phoenix criterion produced 4.1 percent false negatives. Projecting this figure to a population of one thousand reveals the Mini-STAL, utilizing the Phoenix criterion, could miss approximately forty-one students in need of further diagnostic and/or language intervention. Clearly, this percentage of false negatives (4.1 percent) exceeds Hamilton's (1974) ideal rate and indicates the experimental Phoenix criterion does not successfully identify those students with possible language problems.

In looking at the total number of students who failed both tests, as compared to the number of false negatives using the Phoenix criterion, it becomes apparent that more students passed the Mini-STAL 
and failed the STAL than students who failed both tests. This means that more students with undetected language problems (eleven) slipped through the screening test than students who were identified as having possible language problems (nine). Thus, 55 percent of these students would not benefit from services they need, again indicating the Phoenix criterion does not successfully identify those students with language problems.

Conclusion

It appears that Prather's criterion exceeds the ideal amount of false positives and the Phoenix criterion exceeds the ideal amount of false negatives. Thus, a practicing Speech-Language Pathologist who intends to use this screening device alone must deal with "trade-offs." If the clinician were to use Prather's criterion, he/she would be forced to spend a considerable amount of clinical time diagnostically testing those students who failed the test, yet had no language problems (false positives). Assuming an average diagnostic session requires forty-five minutes, this would mean approximately fifty additional hours in needless diagnosis. On the other hand, if a clinician should decide to use the Phoenix criterion, he/she would risk missing 55 percent of those students in need of further language diagnosis and/or intervention.

Given this choice, this investigator feels it would be well worth the clinician's time to use Prather's established criterion when administering the Mini-STAL. This screening device would screen out approximately 75 percent of the students with normal language. The remaining 25 percent could then be screened utilizing the STAL to 
determine those students who warrant further diagnostic testing. 


\author{
CHAPTER V \\ SUMMARY AND IMPLICATIONS
}

SUMMARY

This study was designed to determine whether varying criterion for pass/fail on the Mini-Screening Language Test for Adolescents (Mini-STAL) would increase accuracy of predicting outcome of the Screening Test of Adolescent Language (STAL). The Mini-STAL was developed by Prather et al. (1981) to identify rapidly those students between grades six through twelve who are in need of language intervention. Using Prather's established criterion (one or more errors equal failure), the Phoenix school district (Prather, 1981) found that too many of their school population (20 percent) were failing the Mini-STAL. Thus, they established an experimental criterion (two or more errors equal failure) to identify those students with language problems. The present study sought to determine what proportion of students with language disorders was not detected by the Mini-STAL and what proportion of students without language disorders failed the Mini-STAL using the two criteria.

Subjects for this investigation were 287 students attending the seventh, eighth, and ninth grades at Raymond Brown Junior High School, Hillsboro School District, Hillsboro, Oregon, in the fall of 1981. Nineteen of these students were eliminated from the study due to the ambiguous nature of the manual in determining their pass/fail scores 
for Subtest IV (Proverb Explanation) on both tests, leaving a total of 268 subjects in the study.

The standardized instrument used to assess whether a student was in need of further diagnosis and/or intervention was the Screening Test of Adolescent Language (STAL) by Prather et al. (1980). Results of the STAL were compared with results of the Mini-STAL using the sets of criteria discussed above. Analysis of Prather's established criterion showed the Mini-STAL produced sixty-six false positives or 24.6 percent of those tested passed the Mini-STAL but failed the STAL. Four false negatives or 1.4 percent of the students failed the STAL and passed the Mini-STAL.

Analysis of the Phoenix experimental criterion revealed the Mini-STAL produced six false positives or 2.3 percent of those tested passed the Mini-STAL but failed the STAL. Eleven false negatives or 4.1 percent of those tested failed the STAL but passed the Mini-STAL.

Prather's established criterion produced too large a proportion of false positives to be considered a valid screening test of language abilities, and the experimental Phoenix value produced too large a proportion of false negatives to meet the standards for an ideal screening instrument. Thus, varying the criterion on the Mini-STAL does not increase the accuracy of predicting outcome of the STAL. Hence, this investigator would recomend utilizing the Prather criterion initially; then further screening of the false positives may be completed utilizing the STAL to reduce excessive false positives. This procedure would need to be tested empirically. 


\section{IMPLICATIONS}

A paucity of research, as noted in a review of the literature, exists in the area of adolescent language. Research is needed in designing both screening and diagnostic instruments specifically for this population.

The Mini-Screening Language Test for Adolescents (Prather et al., 1981) was derived totally from an item analysis of data obtained in the standardization of the complete Screening Test of Adolescent Language (Prather et al., 1980). The five items selected were passed by the majority of students at each grade level. The results of this investigation lend question to whether one may assume failure of one of these items resembles failure of the corresponding subtest on the STAL. Based on these results, this investigator believes broader standardization and validation studies need to be conducted on both the STAL and the Mini-STAL prior to clinical use. These studies should utilize students representing I) all grades between the sixth and twelfth and 2) a population encompassing a wider geographical area.

Research in the area of scoring reliability of both tests (MiniSTAL and the STAL) may be useful in determining whether inter-examiner reliability is accurate. Additional research may focus on determining the effectiveness of the Mini-STAL when compared to differing control tests. Finally, a replication of the present study should be conducted to verify consistency of results.

If the mini-screening test were used clinically, it would be well worth the clinician's time to use Prather's established criterion. 
It is recommended that the Mini-STAL be used initially to screen-out approximately 75 percent of the students with normal language. The remaining 25 percent should be screened again utilizing the complete STAL to determine those students who warrant further diagnostic evaluation. This method needs to be established empirically. 
B I B L I O G R A P H Y 


\section{BIBLIOGRAPHY}

BAKER, H., and LELAND, B., Detroit Tests of Learning Aptitude. Indianapolis: Bobbs-Merrill Co., 1967.

BANNATYNE, A., Language, reading, and learning disabilities. Springfield, Ill.: Charles C. Thomas, 1971.

BAREN, M., LIEBL, R., and SMITH, C., Overcoming learning disabilities: A team approach. Reston, Va.: Reston Publishing Co., 1978.

BRENNER, A. C., The standardization of a language screening test for use with normal and learning disabled junior high students. Master's thesis, Arizona State University, 1979.

BYERS BROWN, B. (Ed.), Editor's note. British Journal of Disorders of Communication, 1976, 11:1.

CARROLL, J. B., The study of language: A survey of linguistic and related disciplines in America. Cambridge, Mass.: Harvard University Press, 1953.

CHOMSKY, N. A., Aspects of the theory of syntax. Cambridge, Mass.: MIT Press, 1965.

CRUICKSHANK, W. M., BENTZEN, F. A., RATZEBURG, F. H., and TANNHAUSER, M. T., A teaching method for brain-injured and hyperactive children. Syracuse, N.Y.: Syracuse University Press, 1962.

DUNN, L. M., Peabody Picture Vocabulary Test. Circle Pines, Minn.: American Guidance Service, 1965.

GERBER, A., and BRYEN, D. N., Language and learning disabilities. Baltimore: University Park Press, 1981.

GORDON, M., Lecture notes in SP 583: Speech, Language and Hearing in the Schools. Portland State University, Spring 1981.

HAMILTON, P., Validation of the Oregon School Entrance Speech Screening Test. Master's thesis, Portland State University, 1974.

HEWARD, W. L., and ORLANSKY, M. D., Exceptional children. Columbus, Ohio: Charles E. Merrill Pub. Co., 1980.

IRWIN, J. V., MOORE, J. M., and RAMPS, D. L., Nonmedieval diagnosis and evaluation. In J. V. Irwin and M. Marge (Eds.), Principles of childhood language disabilities. Englewood Cliffs: Prentice Hal1, Inc., 1972. 
JONES, L., and HEALEY, M., Problems of categorization in state laws and regulation. Language Speech and Hearing Services in Schools, $1974,5,253-257$.

KIRK, S. A., MCCARTHY, J. J., and KIRK, W. D., Illinois Test of Psycholinguistic Abilities. Rev. ed. Urbana: University of Illinois Press, 1969.

KLEFFNER, G. B., Language disorders in children. In C. Shewan (Ed.), Speech and language disorders. New York: Harper and Row Pub. Inc., 1978 .

MARGE, M., The general problem of management and corrective education. In J. Irwin and M. Marge (Eds.), Principles of childhood language disabilities. Englewood Cliffs: Prentice-Hall, Inc., 1972 .

MCGRADY, H. J., and OLSON, P. A., Visual and auditory learning processes in normal children and children with learning disabilities. Learning Disorders, 1968, 4, 371-394.

MECHAM, J. J., JEX, J. L., and JONES, J. D., Utah Test of Language Development. Rev. ed. Salt Lake City: Communication Research Assn., 1967.

MERCER, C., Children and adolescents with learning disabilities. Columbus, Ohio: Charles E. Merrill Pub. Co., 1979.

MYKLEBUST, H. R., Auditory disorders in children. New York: Grune and Stratton, 1954 .

MYKLEBUST, H. R., Development and disorders of written language. New York: Grune and Stratton, 1964.

National Advisory Neurological Diseases and Stroke Council, Human communication and its disorders: An overview. Bethesda: National Institute of Neurological Diseases and Stroke, 1969.

NEAL, W. R., Speech pathology services in the secondary schools. Language Speech and Hearing Services in Schools, 1976, 7, 6-16.

NE IDECKER, E. A., School programs in speech-language organization and management. Englewood Cliffs: Prentice Hall, Inc., 1980.

ORTON, S. T., Reading, writing and speech problems in children. New York: Norton, 1937.

PACKOUZ, S. J., Validation of the Preschool Speech and Language Screening Test. Master's thesis, Portland State University, 1975 .

PERKINS, W. H., Speech pathology: An applied behavior science. Saint 
Louis: The C. V. Mosby Company, 1977.

PRATHER, E., Personal letter to Karen Kumpula about mini-screening test, dated 4 June 1981.

PRATHER, E., BREECHER, S., STAFFORD, M., and WALLACE, W., Screening Test of Adolescent Language. Seattle: University of Washington Press, 1980 .

PRATHER, E., BRENNER, A., and HUGHES, K., A mini-screening test for adolescents. Language Speech and Hearing Services in Schools, $1981,12,67-73$.

ROSENBERG, S., Problems of language development in the retarded. In H. C. Haywood (Ed.), Social-Cultural Aspects of Mental Retardation. New York: Appleton-Century-Crofts, 1970.

SITKO, M. C., and GILLESPIE, P. H., Language and speech difficulties of the adolescent learning disabled. L.D. Series 非2. Paper presented at Montgomery County Intermediate Unit Conference on Learning Disabilities in the Secondary Schools, March 1975.

STRAUSS, A. A., and KEPHART, N. C., Psychopathology and education of the brain-injured child, Vol. II: Progress in theory and clinic. New York: Grune and Stratton, 1955.

Task Force Report on traditional scheduling procedures in schools. Language Speech Hearing Services in Schools, 1973, 4, 100-108.

THORUM, A., Fullerton Language Assessment Test for Adolescents. Pa10 Alto: Consulting Psychological Press, 1979.

THORUM, A., Language assessment instrument: Infancy through adulthood. Springfield, Ill.: Charles C. Thomas, 1981 .

U.S., CONGRESS, HOUSE, The Children with Specific Learning Disabilities Act of 1969. Pub. L. 91-230.

U.S., CONGRESS, HOUSE, The Education for All Handicapped Children Act of 1976. Pub. L. 94-142.

VOGEL, S. A., Syntactic abilities in normal and dyslexic children. Journal of Learning Disabilities, 1974, 7, 103-109.

WIIG, E., and HARRIS, S. P., Perception and interpretation of nonverbally expressed emotions by adolescents with learning disabilities. Perceptual Motor Skil1s, 1974, 38, 239-245.

WIIG, E. H., and SEMEL, E. M., Logico-grammatical sentence comprehension by adolescents with learning disabilities. Perceptual Motor Skills, 1974, 38, 1331-1334. 
WIIG, E. H., and SEMEL, E. M., Language disabilities in children and adolescents. Columbus, Ohio: Charles E. Merrill Pub. Co., 1976.

WIIG, E. H., and SEMEL, E. M., Language assessment and intervention for the learning disabled. Columbus, Ohio: Charles E. Merrill Pub. Co., 1980 .

WOOD, N., Verbal learning: Dimensions in early learning series. San Rafael, Calif.: Dimensions Publishing Co., 1969. 
A P P E N D I C E S 


\section{APPENDIX A}

\section{PERMISSION REQUEST LETTER}

\section{Dear Parents:}

I am a graduate student at Portland State University and I am conducting a study regarding identification of Junior High students with language disorders. I am attempting to find out how well a short-formed test will identify those students needing language intervention. The results of this study should help Teachers and SpeechLanguage Pathologists identify and subsequently provide services to Junior High students in need of language intervention.

This study can be accomplished by administration of the following evaluation instruments: The Screening Test of Adolescent Language ( 7 minutes) and the Mini-Screening Language Test for Adolescents (1 minute).

The evaluation will take approximately eight minutes of your son/daughter's time. The evaluation will be done by myself, Denice Milholland, as well as three trained graduate students from the Speech and Hearing Sciences area, Department of Speech Communication of Portland State University. Only the appropriate school personnel will have access to any results. In no way will your son/daughter's name be used in reporting the results of this study.

Please sign below indicating your approval, and return with your child to school tomorrow.

Thank you for your help.

Denice Milholland

Graduate Student

Speech and Hearing Sciences

Portland State University

CHILD'S NAME

PARENT'S SIGNATURE

STUDENT'S SIGNATURE 
APPENDIX A (cont.)

\section{DATE}

PER IOD 非

TEACHER'S NAME 
SCREEN ING TEST OF ADOLESCENT LANGUAGE SCORE SHEET

\section{VOCABULARY}

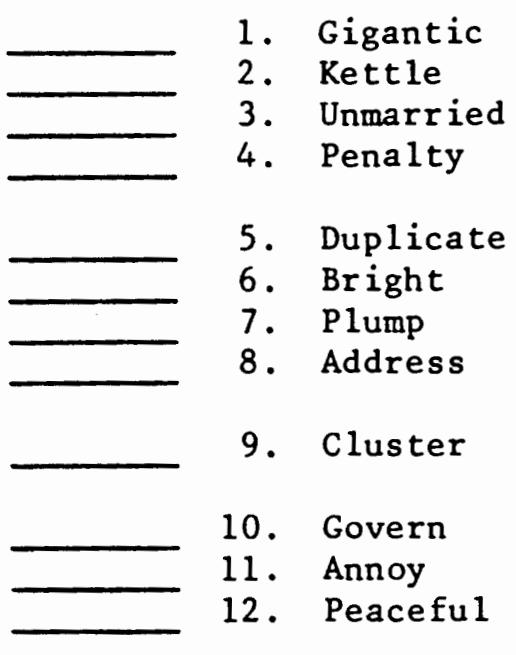

TOTAL I
The room is gigantic

The kettle is copper.

My teacher is unmarried.

What is the penalty

for breaking the rule?

Can you duplicate this?

The diamond was bright.

The child is plump.

He made a political

address.

I saw a cluster of

students.

She will govern.

They annoy him.

It was a peaceful

evening.

II. AUDITORY MEMORY SPAN

1. The fire drill that we had last week/ turned out to be the real thing.

2. The school on the west side of town/ has more new students than our own school.

3. Last night I went to a movie with my friend/ at the theater that takes coupons.

TOTAL II

III. LANGUAGE PROCESSING

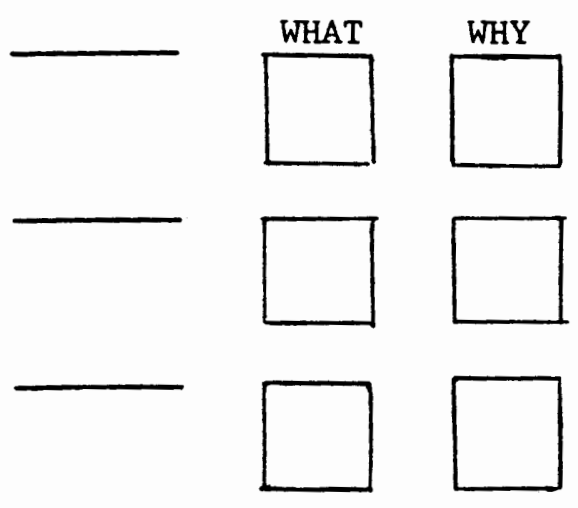

1. The sun was shining so brightly last week on Tuesday that I had to wear my sunglasses in the movie theater.

2. I went with my sister to the shoe store to buy a pair of combat boots to wear to the Junior Prom.

3. After climbing up ten flights of stairs two steps at a time yesterday morning, the man finally reached the basement. 
APPENDIX B (cont.)

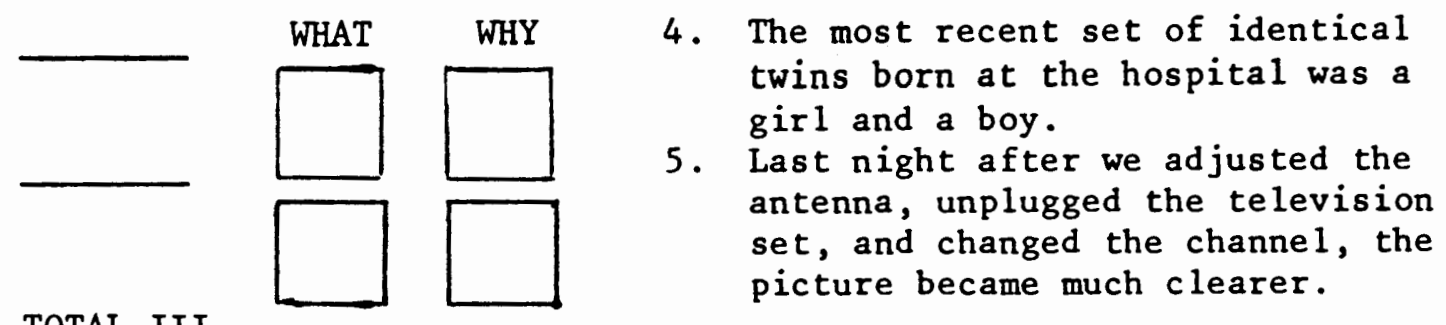

TOTAL III

\section{PROVERB EXPLANATION}

1. Practice makes perfect.

2. Actions speak louder than words.

3. Better late than never.

TOTAL IV

TOTAL TEST SCORE

NAME B IRTHDATE GRADE

DATE EXAMINER

TOTAL TEST SCORE Vocabulary Aud. Memory Lang. Probe Prov. Expl.

RECOMENDATIONS : Pass-No further testing Fail-Further assessment

MINIMUM PASSING SCORES FOR THE SCREENING TEST OF ADOLESCENT LANGUAGE

TOTAL TEST SCORE

Vocabulary Auditory Memory Span Language Processing Proverb Explanation
GRADES 6-8

11 pass responses

5 pass responses

1 pass response

2 pass responses

1 pass response
GRADES 9-12

13 pass responses

6 pass responses

1 pass response

2 pass responses

1 pass response 
APPENDIX C

MINI-SCREENING LANGUAGE TEST FOR ADOLESCENTS SCORE SHEET

NAME

I. VOCABULARY

1. Gigantic

2. Plump

The room is gigantic.

The child is plump.

TOTAL I

II. AUDITORY MEMORY SPAN

The fire drill that we had last week/turned out to be real thing.

TOTAL II

III. LANGUAGE PROCESSING

WHAT WHY

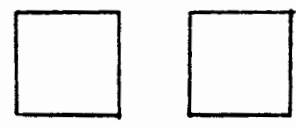

1. The sun was shining so brightly last week on Tuesday that I had to wear my sunglasses in the movie theater.

TOTAL III

IV. PROVERB EXPLANATION

1. Practice makes perfect.

TOTAL IV 